\section{AB0606 LONG-TERM BIOLOGICAL TREATMENT IN LARGE VESSELS VASCULITIS: A RETROSPECTIVE SINGLE- CENTER STUDY ON 30 PATIENTS FROM 2011 TO 2018}

Francesca Regola ${ }^{1}$, Giovanni Bosio ${ }^{2}$, Elisabetta Cerudelli ${ }^{2}$, Angela Tincani ${ }^{1}$, Paola Toniati'. ${ }^{1}$ U.O. Rheumatology and Clinical Immunology, ASST Spedali Civili of Brescia, Department of Clinical and Experimental Sciences, Brescia, Italy; ${ }^{2}$ Department of Nuclear Medicine, Spedali Civili of Brescia, Brescia, Italy

Background: Glucocorticoids (GC) are the mainstay in the treatment of large vessels vasculitis (LVV), while conventional immunosuppressants have modest GC-sparing effect. Recent studies show that biological drugs could represent a valid therapeutic option, especially in patients with severe and/or relapsing LVV. Their role in the treatment of LVV is expanding, but only few data are available on their long-term efficacy and safety $[1,2]$

Objectives: Our aim is to describe the 8 years' experience of a single Italian center in biological treatment of patients with large vessels vasculitis (LVV).

Methods: We collected retrospectively clinical data from 30 patients affected by LVV and treated with biological drugs. Data from 18F-FDG PET and CT or MRI associated with improvement of clinical and inflammatory index (ESR and CRP) were used as criteria of response to treatment.

Results: Between 2011 and 2018 we treated 30 LVV patients (22 women and 8 men) with biological drugs: 10 patients with Takayasu arteritis (TAK), 17 patients with large-vessel giant cell arteritis (LV-GCA) and 3 patients with aortitis. The median age $\left(10^{\text {th }}-90^{\text {th }}\right.$ percentile) at the diagnosis was 63 (21-79) years. Biological treatment was started right after the diagnosis in 15 patients, while 15 patients had a long-standing relapsed disease (time between diagnosis and biological therapy 6 (1-43) months). The mean follow-up time of patients was 26 (4-72) months.

Anti-TNF- $\alpha$ drugs (infliximab, adalimumab, golimumab) were used in 9 patients; while anti-IL6r (tocilizumab) was used in 30 patients. During the follow up, 9 patients (23\%) switched to another biologic for relapse of the disease or for infusive adverse reactions; in 3 cases multiple switches were made.

Infliximab (IFX) was used in 7 patients for a median period of 12 (3-33) months: 3 patients archived stable remission, 3 had an infusive adverse reaction, 1 had a relapse of the disease after 60 months of therapy. Adalimumab (ADA) was used in 3 patients and then suspended in all of them for relapse of the disease after 3, 12 and 93 months of therapy, respectively. Golimumab was used in 2 patients: one suspended therapy for developing follicular thyroid cancer, one switched to another biologic for persistent active disease.

Tocilizumab (TCZ) was used in all 30 patients for a median period of 20 (4-54) months: in 25 cases it was the first line therapy, in the other 5 cases it was used after an anti-TNF- $\alpha$ drug. 25 patients out of $30(84 \%)$ archived stable remission and in 6 of them a dose tapering was possible, with no sign of relapse.

Three patients in TCZ had an adverse reaction; one developed a uveitis and one had a relapse of TAK.

In our last examination 29 out of 30 patients in biological therapy demonstrated a good control of the disease with clinical improvement, also confirmed by PET, TC and/or MRI, and reduction of inflammatory index (ESR and CRP), compared to before starting treatment. Biologics also demonstrated an important steroid sparing effect: mean prednisone dose at the beginning of treatment was $25 \mathrm{mg} /$ day (12-50), while at the last follow-up was $6 \mathrm{mg} /$ day $(1-15) \quad(p<0.0001$; Wilcoxon test)

Conclusion: In our cohort of 30 patients biological treatments demonstrated long-term efficacy and acceptable safety profile and important steroid sparing effect.

\section{REFERENCES}

[1] Pazzola G, et al. Rev Med Interne, 2016

[2] Samson M, et al. Eur J Intern Med, 2018

Disclosure of Interests: Francesca Regola: None declared, Giovanni Bosio: None declared, Elisabetta Cerudelli: None declared, Angela Tincani Consultant for: UCB, Pfizer, Abbvie, BMS, Sanofi, Roche, GSK, AlphaSigma, Lilly, Jannsen, Cellgene, Novartis, Paola Toniati: None declared DOI: 10.1136/annrheumdis-2019-eular.4384

\section{AB0607 \\ SELF-MANAGEMENT BEHAVIOURS IN ANCA- ASSOCIATED VASCULITIS: SECONDARY ANALYSIS OF INTERVIEW DATA}

Tim Reynolds ${ }^{1}$, Emma Dures ${ }^{2}$, Sue Ashdown ${ }^{3}$, Peter Cronholm ${ }^{4}$,

Raashid Luqmani ${ }^{5}$, Peter Merkel ${ }^{6}$, Nataliya Milman ${ }^{7}$, Jacqueline Peck ${ }^{3}$,

Joanna Robson'. ' University Hospitals Bristol NHS Foundation Trust, Bristol,

United Kingdom; ${ }^{2}$ University of the West of England, Bristol, United Kingdom;

${ }^{3}$ Patient partner, Oxford, United Kingdom; ${ }^{4}$ University of Pennsylvania Perelman School of Medicine, Philadelphia, United States of America; ${ }^{5}$ University of Oxford, Oxford, United Kingdom; ${ }^{6}$ University of Pennsylvania, Philadelphia, United States of America; ${ }^{7}$ Division of Rheumatology, Department of Medicine in Ottawa, Ottawa, Canada

Background: ANCA-associated vasculitis (AAV) is a significant cause of morbidity and mortality. Meeting the challenges of AAV effectively requires patients to engage in self-management, including medical management, role management, and emotional management. ${ }^{1}$ Self-management is recognised as a key aspect of chronic disease management and forms an important part of the National Health Service 5-year forward plan and the UK strategy for rare diseases. ${ }^{2,3}$ Nonetheless, there has been limited specific research into the role of self-management in the AAV literature.

Objectives: To explore experiences and views of self-management amongst AAV patients.

Methods: A secondary analysis of all interview transcripts from a previous project exploring health-related quality of life in relation to AAV was performed. ${ }^{4}$ Deductive analysis was used to map appropriate areas discussed by patients to the self-management framework proposed by Lorig and Holman. ${ }^{1}$ Inductive analysis was used to identify emergent themes that did not fit into this framework.

Results: Interview data were collected from 50 patients with AAV (25 men), from the UK $(n=18)$, USA $(n=17)$ and Canada $(n=15)$. Diagnoses included GPA $(n=26)$, EGPA $(n=17)$ and MPA $(n=7)$. Thirty-four patients were diagnosed within the last 2 years and 16 were diagnosed more than 2 years ago. ${ }^{4}$

From the core tasks proposed in Lorig and Holman's framework, patients with AAV appear to attribute particular importance to maintaining life roles and to a lesser extent medication management and dealing with the emotions of chronic disease. Core skills necessary to self-manage in AAV include learning to take action as part of self-efficacy, forming productive health-care partnerships, learning about decision making (requiring disease and self-awareness), utilising resources effectively, and problemsolving.

Three themes emerged that were not included in Lorig and Holman's framework that respondents related to self-management abilities including: 1) support received from family, support groups, and religion; 2) the influence of pre-morbid personality factors; 3) the role patients attributed to developing a foundation of specific AAV knowledge in their subsequent ability to self-manage.

Conclusion: Patients with AAV self-manage in a variety of ways and their needs may change over time. Patients may benefit from support to help manage changing life roles and to deal with the challenges of having a chronic disease. Over time, support may need to shift focus onto core skills including recognising when to take action; forming effective partnerships with healthcare providers, family, and friends; adaptations to day-to-day changes in their condition; utilising resources appropriately; and strategies for problem-solving.

\section{REFERENCES}

[1] Lorig, K.R. and Holman, H.R., 2003. Self-management education: history, definition, outcomes, and mechanisms. Annals of behavioral medicine, 26 (1), pp.1-7.

[2] NHS England. Five year forward view. Oct 2014. Available from:https:// www.england.nhs.uk/ourwork/futurenhs/

[3] UK Strategy for Rare Diseases. Department of Health, 2013.

[4] Robson, J.C., Dawson, J., Cronholm, P.F., Milman, N., Kellom, K.S., Ashdown, S., Easley, E., Farrar, J.T., Gebhart, D., Lanier, G. and McAlear, C. A., 2018. Health-related quality of life in ANCA-associated vasculitis and item generation for a disease-specific patient-reported outcome measure. Patient related outcome measures, 9, p.17.

Disclosure of Interests: Tim Reynolds: None declared, Emma Dures Grant/research support from: Has previously received an independent learning grant from Pfizer, however the work has been completed and 
the grant has been closed., Sue Ashdown: None declared, Peter Cronholm: None declared, Raashid Luqmani Grant/research support from: Roche, Vifor and GSK, Peter Merkel: None declared, Nataliya Milman: None declared, Jacqueline Peck: None declared, Joanna Robson: None declared

DOI: 10.1136/annrheumdis-2019-eular.7135

\section{\begin{tabular}{l|l} 
AB0608 & TOCILIZUMAB TREATMENT FOR LARGE VESSELS
\end{tabular} VASCULITIS: REAL LIFE PRELIMINARY EXPERIENCES}

Giulia Righetti, Vincenzo Venerito, Maria Giannotta, Giuseppe Lopalco, Margherita Giannini, Fabio Cacciapaglia, Laura Coladonato, Florenzo lannone. Bari, Department of Emergency and Organ Transplantations-Rheumatology Unit, Bari, Italy

Background: IL-6r targeting therapy has been proven to be effective and safe in Giant Cell Arteritis (GCA) as well in Takayasu Arteritis (TA) in RCTs, probably because of the similar pathologic findings and vessel size (Large Vessel Vasculitis, LVV). However, real world data are scarce. Objectives: The aim of the study was to evaluate the effectiveness of Tocilizumab for LVV in real life settings.

Methods: We retrospectively evaluated, from 2011 to 2017, the outcomes (including glucocorticoid dosage) in patients affected by LVV (according to 1990 ACR classification criteria) who received $8 \mathrm{mg} / \mathrm{kg}$ iv Tocilizumab (TCZ) monthly, due to the inadequate response to immunosuppressant. Demographic and clinical characteristics and laboratory findings were collected at baseline and consecutive follow up visits, over 52 weeks. Statistical analysis was performed using the GraphPad Software ver. 6.0 (San Diego CA USA) using appropriate tests.

Results: We analyzed n.10 patients (6/10 GCA, 4/10 TA) with mean age $( \pm$ SD) $56 \pm 21$ years and mean disease duration $41 \pm 38$ months. Eight out of 10 patients were female. Over the entire observation period, 7/10 also received concomitant methotrexate (mean dose $12.8 \pm 2.7 \mathrm{mg} / \mathrm{week}$ ) while 2/10 received azathioprine (100 mg/day). Median (IQR) prednisone equivalent dose at baseline was $22.5(10-25) \mathrm{mg} /$ day. At baseline, median ESR was $49(31-58) \mathrm{mm} / \mathrm{h}$ and median CRP level was 15.4 (1.95-28.53) $\mathrm{mg} / \mathrm{l}$. Upon TCZ treatment we observed a good disease control in absence of headache, fever and other LVV clinical signs through 52-week follow up. At 52 weeks, we observed a significant reduction of ESR down to $6.5(2.75-12.25) \mathrm{mm} / \mathrm{h}$ as well as of CRP level, down to $1.5(0.67-3.47) \mathrm{mg} / \mathrm{l}(\mathrm{p}<0.001)$. A meaningful steroid sparing effect was also achieved as a significant reduction in prednisone dose down to 5 $(1.87-6.25) \mathrm{mg} /$ day $(\mathrm{p}<0.001)$. During the 52 -week follow up period, 3 patients discontinued TCZ treatment for side effects: 1 for severe neutropenia (at 12 weeks), 1 for hemorrhagic pancreatitis (after 24 weeks), and 1 for diverticulitis (after 52 weeks)

Conclusion: In our real life experience iv TCZ was effective and safe in LVV treatment, with a good disease control and a significant steroid-sparing effect. Our preliminary findings need to be confirmed in larger cohorts and prolonged follow-up.

\section{REFERENCES}

[1] Stone JH, Tuckwell K, Dimonaco S, Klearman M, Aringer M, Blockmans D, Brouwer E, Cid MC, Dasgupta B, Rech J, Salvarani C, Schett G, Schulze-Koops H, Spiera R, Unizony SH, Collinson N. Trial of Tocilizumab in Giant-Cell Arteritis. N Engl J Med. 2017 Jul 27;377(4):317-328. doi: 10.1056/NEJMoa1613849. PubMed PMID: 28745999

Disclosure of Interests: giulia righetti: None declared, vincenzo venerito: None declared, maria giannotta: None declared, Giuseppe Lopalco Speakers bureau: SOBI, BMS, margherita giannini: None declared, Fabio Cacciapaglia: None declared, Laura Coladonato: None declared, Florenzo lannone Consultant for: $\mathrm{F}$ lannone has received consultancy fees and/or speaker honoraria from Pfizer, AbbVie, MSD, BMS, Novartis, Lilly, UCB outside this work, Speakers bureau: $F$ lannone has received consultancy fees and/or speaker honoraria from Pfizer, AbbVie, MSD, BMS, Novartis, Lilly, UCB outside this work

DOI: 10.1136/annrheumdis-2019-eular.2395

\section{AB0609}

NAILFOLD VIDEO CAPILLAROSCOPY AS A POTENTIAL DIAGNOSTIC TOOL IN SYSTEMIC VASCULITIS

Doron Rimar ${ }^{1}$, Francesca Ingegnoli ${ }^{1}$, Ori Rimar ${ }^{1}$, Itzhak Rosner ${ }^{1}$

Michael Rosenbaum ${ }^{1}$, Lisa Kaly ${ }^{1}$, Nina Boulman ${ }^{1}$, Abid Awisat ${ }^{1}$, Gleb Slobodin ${ }^{2}$

${ }^{1}$ Bnai-Zion Medical Center, Rheumatology, Haifa, Israel; ${ }^{2}$ Istituto Gaetano Pini,

Division of Clinical Rheumatology, Milan, Italy

Background: Vasculitides are formally classified by artery size: large, medium or small, yet some overlap is evident as in Takayasu, a large vessel vasculitis manifesting also in retinal arterioles. Nailfold videocapillaroscopy (NVC) enables us to inspect changes in microvasculature. Only several small uncontrolled case series of light capillary microscopy in adult patients with vasculitis were reported in the literature, describing avascular areas and microhemorrhages in granulomatosis with polyangiitis (GPA) patients [1-2] and in [4] Behcet disease, and thin and tortuous capillaries in Takayasu arteritis [5].

Objectives: To characterize nailfold capillary changes by NVC in patients with autoimmune vasculitis compared to healthy controls.

Methods: Consecutive autoimmune vasculitis patients fulfilling the ACR criteria and age and gender matched healthy controls were evaluated by NVC using Optilia Mediscope with a magnification of X200. Patients with peripheral artery disease and ischemic heart disease were excluded. Capillaroscopy images were centrally analyzed. NVC was analyzed, noting: architecture, number of capillaries per field, capillary width, capillary morphology, microhemorrhages, peri-capillary stippling (PCS)- hemosiderin deposits probably representing former capillary leak, slow capillary flow ("rolling" or sludging of red blood cells) and avascularity. Continuous data are presented as the mean \pm SD. Categorical variables are presented as frequencies and percentages. Comparisons of continues variables were made using 2-tailed t-tests and differences between groups by a 1-Way ANOVA.

Results: Seventeen patients with active vasculitis, 8 patients with vasculitis in remission (11 polyarteritis nodosum, 2 GPA, 3 eosinophilic granulomatosis with polyangiitis, 2 microscopic polyangiitis, 2 Takayasu, 3 Sjogren vasculitis (one with cryoglobulinemia), 1 primary central nervous system vasculitis and 1 lupus vasculitis) were compared to 25 age and sex matched healthy controls. The mean age ( $59 \pm 18$ vs. $51 \pm 19$ vs. 52 $\pm 15)$, and the percent of females $(53 \%, 50 \%, 60 \%)$, were similar between the groups.

Patients with active vasculitis demonstrated higher rate of "rolling", $74.1 \%$ \pm 27 vs. $12.5 \% \pm 22$ vs. $6.5 \% \pm 12.7, \quad \mathrm{p}<0.001$; microhemorrhages or PCS $30.1 \% \pm 26.4$ vs. $1.5 \% \pm 4.5$ vs. $1.9 \% \pm 1, \mathrm{p}<0.05$, which reversely correlated with disease duration $r=-0.4, P=0.05$; avascular areas $76 \% \pm 19.5$ vs. $23.4 \%$ \pm 28 vs. $26 \% \pm 18.5, \quad p<0.01$ and neoangiogenesis $57 \% \pm 23 \%$ vs $26.5 \%$ \pm 22.5 vs. $6 \% \pm 10.5, p<0.01$. PCS was observed exclusively in 5 of 17 patients with active vasculitis.

Conclusion: Patients with active vasculitis demonstrate capillary abnormalities, namely: "rolling", microhemorrhages, avascular areas and neoangiogenesis. PCS may be a specific sign of active vasculitis. NVC is an easy, readily available additive tool in the management of vasculitis. Further studies are needed to ascertain the role of NVC in vasculitis.

\section{REFERENCES}

[1] Sendino Revuelta A, Barbado Hernández FJ, Torrijos Eslava A, González Anglada I, Peña Sánchez de Rivera JM, Vázquez Rodríguez JJ. Capillaroscopy in vasculitis.An Med Interna. 1991;8(5):217-20. Spanish.

[2] HJ Anders, C Headecke, T Sigl, K Kruger. Avascular areas on nailfold capillary microscopy of patients with Wegener's granulomatosis. Clin Rheumatol. 19:86-8, 2000

[3] Aytekin S, Yuksel EP, Aydin F, Senturk N, Ozden MG, Canturk T, Turanli AY. Nailfold capillaroscopy in Behçet disease, performed using videodermoscopy. Clin Exp Dermatol. 2014;39(4):443-7.

[4] Javinani A, Pournazari M, Jamshidi AR, Kavosi H. Nailfold videocapillaroscopy changes in Takayasu arteritis and their association with disease activity and subclavian artery involvement. Microvasc Res. 2019;122:1-5

Disclosure of Interests: None declared

DOI: 10.1136/annrheumdis-2019-eular.2197 